\title{
Microbial Profile of Ventilator Associated Pneumonia in a Medical Intensive Care Unit of a Tertiary Care Hospital in Bangalore
}

\author{
Abhilekha Bishwas ${ }^{1}$, Hemavathi² ${ }^{2}$ Poornima Shenoy ${ }^{3}$ \\ ${ }^{1}$ Department of Microbiology, SIMS\&RC, Bangalore, Karnataka, India. ${ }^{2}$ Department of Microbiology, SIMS\&RC, \\ Bangalore, Karnataka, India. ${ }^{3}$ Department of Microbiology, SIMS\&RC, Bangalore, Karnataka, India.
}

\section{ABSTRACT}

\section{BACKGROUND}

Ventilator Associated Pneumonia (VAP) is an important infection most often encountered in mechanical ventilation (MV) patients in intensive care units in hospital. VAP occurs in approximately $9-27 \%$ of patients who are intubated. The morbidity and mortality associated with VAP is more inspite of recent advances in diagnosis and accurate management. Emergence of multidrug resistance among the pathogens causing VAP is also contributing to the outcome. We wanted to isolate the bacterial pathogens, study the antibiotic susceptibility pattern of the isolates and detect the presence of drug resistance in various pathogens.

\section{METHODS}

This is a retrospective, cross sectional study done on samples received between 2016 to 2018 among patients on MV for $>/=48$ hours. Endotracheal aspirates were collected from 85 patients with assumed VAP, clinical pulmonary infection score (CPIS) was noted and aerobic quantitative cultures were performed on all samples. VAP was diagnosed by count of pathogenic organisms isolated $>/=10^{5} \mathrm{cfu} / \mathrm{mL}$. Identification and antibiotic susceptibility of the isolates were done as per the standard laboratory procedures. Patients with characteristic features i.e. clinical and radiological signs of pneumonia on admission were excluded from the study.

\section{RESULTS}

50 cases were diagnosed as VAP by CPIS. Gender ratio was 30:20 (male to female) higher incidence $42 \%$ of VAP was seen in the age group of 46-60 years. Majority were Gram negative bacilli; 96\%- Klebsiella 36\%, Acinetobacter 26\% E. coli $16 \%$, Pseudomonas $14 \%$, and Citrobacter $4 \%$ along with coagulase positive Staphylococcus in $4 \%$. Of the 50 VAP patients, single organism was isolated in $92 \%$ and polymicrobial in $8 \%$. Most of the isolates showed resistance to Amoxiclav, Cefepime, Cefixime and Meropenem.

\section{CONCLUSIONS}

Good compliance with VAP bundle adopted in critical care areas by the health care workers will reduce the incidence of VAP. Early and accurate diagnosis, appropriate empirical and specific antimicrobial use may significantly improve patient outcome.

\section{KEY WORDS}

Ventilator Associated Pneumonia (VAP), Multidrug Resistance Pathogen
Corresponding Author: Dr. Abhilekha Bishwas, Elgin Tower-2/6B2, Calcutta Riverside, Batanagar-700140, Kolkata, West Bengal, India. E-mail: honey2571@gmail.com

DOI: $10.14260 /$ jemds/2020/336

Financial or Other Competing Interests: None.

How to Cite This Article:

Bishwas A, Hemavathi, Shenoy P. Microbial profile of ventilator associated pneumonia in a medical intensive care unit of a tertiary care hospital in Bangalore. J. Evolution Med. Dent. Sci. 2020;9(19): 1539-1543, DOI:
Submission 07-03-2020,

Peer Review 22-04-2020,

Acceptance 29-04-2020,

Published 11-05-2020. 


\section{BACKGROUND}

Ventilator-Associated Pneumonia (VAP) a subgroup of hospital acquired pneumonia is highly lethal form contracted by patients on ventilators in hospitals and long term nursing facilities. VAP defined as pneumonia occurring in patients admitted in critical care unit for more than 48 hours after endotracheal intubation and infiltration of mechanical ventilation, including pneumonia developing after extubation. ${ }^{[1]}$

The American Thoracic Society (ATS) consent statement proposes the categorization of VAP - a) early onset: Ventilator associated pneumonia occurring within 4 days of endotracheal intubation and initiation of mechanical ventilation. b) Late onset: Ventilator Associated Pneumonia occurring after 4 days of endotracheal intubation and initiation of mechanical ventilation. This categorization helps predict the implicated pathogen and guided us in the initial empiric therapy with antibiotics. $[2,3]$

VAP is the most common nosocomial infection in the intensive care unit (ICU) with an incidence ranging from 9$27 \%$ in intubated mechanically ventilated patients.[4] VAP may be caused by a wide spectrum of bacterial pathogen may be polymicrobial and rarely by viral or fungal pathogens in immune compromised hosts.[4,5] The etiologic agents of VAP include - Acinetobacter, Pseudomonas spp., Klebsiella spp. and gram positive cocci (Staphylococcus)

Accurate diagnosis of VAP relics a challenge, with no consent on a reference "gold standard" definition, Clinical diagnosis is established based on new or persistent infiltrates on chest radiography plus two or more of the following: A) Purulent tracheal secretions (b) Blood leucocytosis $\left(>12 \times 10^{9}\right.$ white blood cells/L) or leucopenia $\left(<4 \times 10^{9}\right.$ white blood cells/L), (c) Temperature greater than $38.3^{\circ} \mathrm{C}$, recommended by ATS guidelines. $[2,6]$

VAP is hard to analyse, expensive to treat, and extends a patient's stay in the ICU and is associated with significant morbidity and mortality. Timely management with appropriate antibiotic leads a favourable outcome ${ }^{6]}$ thereby reducing the detrimental effects of insufficient antibiotic treatment on the patient prognosis.

Hence, the present study is undertaken to isolate, identify and quantitate bacteria and to perform the antibiotic susceptibility testing from the endotracheal aspirates of the clinically suspected patients of VAP.

\section{Objectives}

1. To estimate the proportion of VAP in 3 years in MICU.

2. To assess the microbial profile and drug susceptibility from the endotracheal aspirates of the clinically suspected patients of VAP.

\section{METHODS}

This was a retrospective, cross sectional study carried out over a period of 3 years, from 2016 to 2018 in the Department of Microbiology from Medical Intensive Care Unit (MICU) patients with clinical notion of ventilator- associated pneumonia. VAP was recognised using Clinical Pulmonary Infection Score (CPIS), which was assessed on a daily basis as long as the patient remained on ventilator support. CPIS> 6 used as diagnostic criteria for VAP

The approval of the ethical committee was obtained and informed consent was taken by the care takers of the patients. No animal experiments were required for the study.

\section{Inclusion Criteria}

Patients $>18$ years and above under Mechanical Ventilation (MV) for $>48$ hours and clinically assumed of having VAP.

\section{Exclusion Criteria}

Patients with clinical and radiological signs indicative of pneumonia on admission.

All critically ill adult patients above the age of 18 years who stayed on mechanical ventilation for more than 48 hours remained included in this study. $0.01 \mathrm{ml}$ of endotracheal sample was inoculated on Blood agar, Chocolate agar and MacConkey agar and plates were incubated overnight at $37^{\circ} \mathrm{C}$ for 24 and 48 hours. Plates with growth were subjected to analysis for bacterial counts and were expressed as colony forming units per ml (CFU/ML). For definite diagnosis of VAP, along with clinical criteria a bacterial count of $10^{5} \mathrm{CFU} / \mathrm{mL}$ of endotracheal aspirate was considered significant. Cultures with lower colony count were considered as colonization or contamination. Identification of the bacterial isolates was done by standard biochemical tests. ${ }^{[7]}$

Antimicrobial sensitivity testing was performed on Muller Hinton Agar and interpreted by means of the Clinical and Laboratory Standards Institute (CLSI) guidelines. ${ }^{[8]}$

\begin{tabular}{|cccc|}
\hline CPIS Points & $\mathbf{0}$ & $\mathbf{1}$ & $\mathbf{2}$ \\
Tracheal secretions & Rare & Abundant & Purulent \\
Leukocyte count & $>4,000$ to & $<4,000$ to & $<4,000$ or $>11,000+$ \\
$\left(\mathrm{mm}^{3}\right)$ & $<11,000$ & $>11,000$ & band forms \\
Temperature $\left({ }^{\circ} \mathrm{C}\right)$ & $>36.5$ to $<38.4$ & $>38.5$ to $<38.9$ & $>39$ or $<36$ \\
$\mathrm{PaO}_{2} / \mathrm{FiO}_{2}$ ratio & $>240$ & - & $\leq 240$ and no ARDS \\
$\left(\mathrm{mmHg}^{\mathrm{m} H}\right.$ & No infiltrate & Diffuse infiltrate & Localized infiltrate \\
Chest radiograph & - & Positive \\
Tracheal aspirate & Negative & - & \\
Culture & Table 1. CPIS: Clinical Pulmonary Infection Scoring [9] \\
\hline \multicolumn{4}{|r}{} \\
\hline
\end{tabular}

\section{Statistical Analysis}

Data collected was compiled in MS excel sheet 2013. Data was analyzed using SPSS version 20. Data was presented using descriptive statistics in percentages, frequencies etc.

\section{RESULTS}

Out of 85 cases studied, 50 cases were diagnosed as VAP by CPIS score. The incidence of VAP in present study was $58.82 \%$.Gender ratio was 30:20 (male to female) shown in Graph 1. 


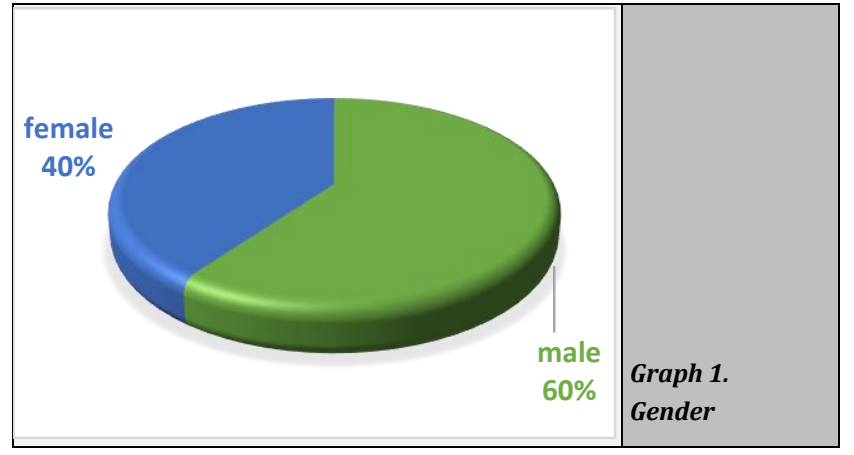

In the age group of 46-60 years, the incidence of VAP was more common $42 \%$ (21/50), followed by $36 \%(18 / 50)$ among $61-85$ years, $14 \%(7 / 50)$ in $31-45$ years and $8 \%$ (4/50 in $18-30$ years. (graph 2 ).

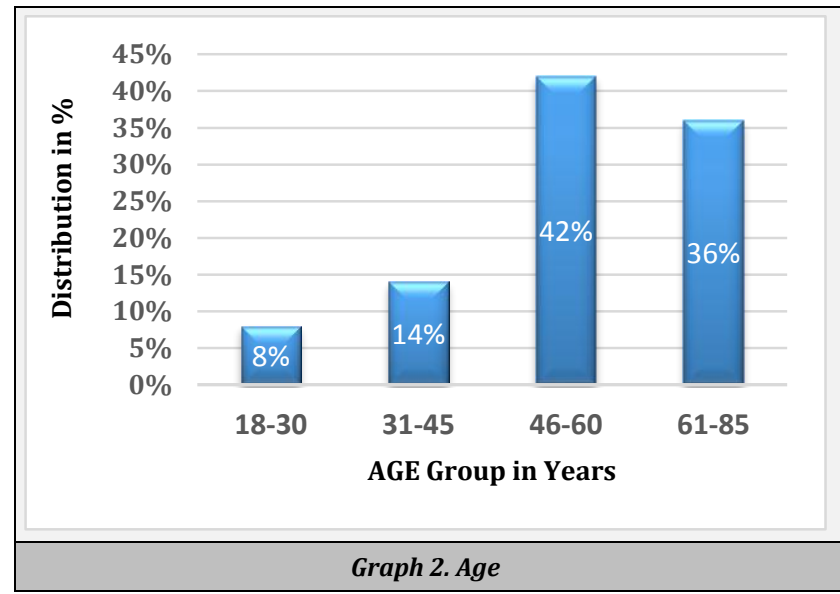

Majority were Gram negative bacilli $96 \%$ (48), the organisms being Klebsiella 18 (36\%), Acinetobacter 13 (26\%), E. coli 8 (16\%), Pseudomonas 7 (14\%), Citrobacter and Staphylococcus aureus (2) $4 \%$ each. Of the 50 VAP patients, single organism was isolated in $92 \%$ (46) and $8 \%$ (4) were polymicrobial is shown in graph 3.

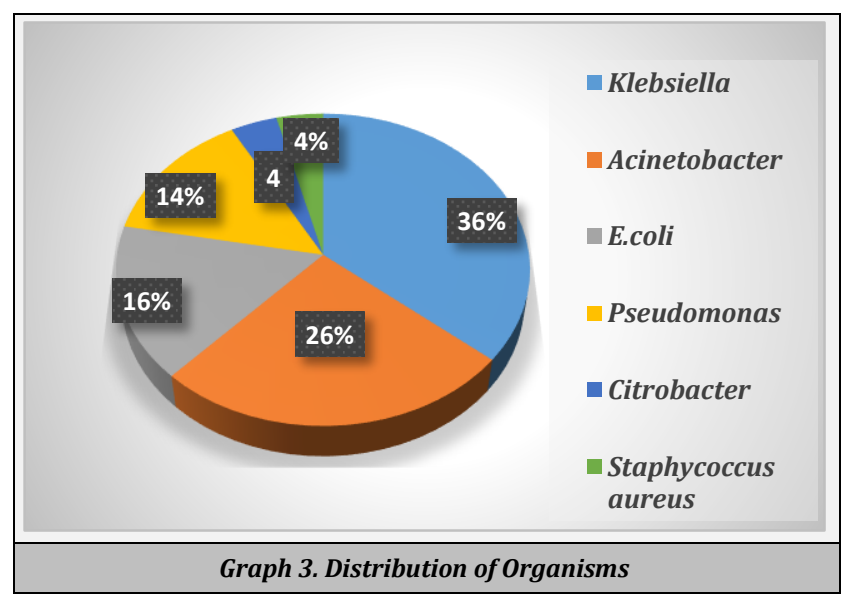

Concurrent predisposing factors were organic poisoning, stroke, road traffic accidents, carcinomas and chronic renal diseases with the mortality rate of $(30 \%)$ in our study.

Resistance pattern: Klebsiella spp. Showed 100\% resistant to Amoxiclav and Cefazolin. Among Carbapenems Imipenem- 22.22\% and Meropenem 44.44\%, and Amikacin resistance $33.33 \%$ were seen. Out of 13 Acinetobacter spp., 4 isolates were multidrug resistance to amikacin, ciprofloxacin, carbapenems and 2 were monoresistant i.e. to carbapenems. E. coli and Pseudomonas and Citrobacter species showed $100 \%$ resistance to Amoxiclav, Cefepime, Cefixime and 25\% and, $29 \%$ to Meropenem. Shown in Table 2.

\begin{tabular}{|c|c|c|c|c|c|}
\hline 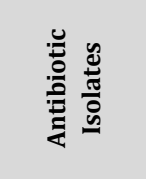 & 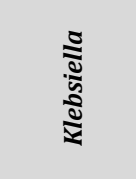 & 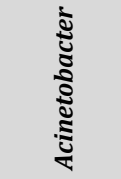 & రิ & 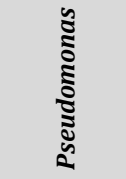 & 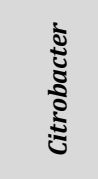 \\
\hline & $\mathrm{n}=18$ & $\mathrm{n}=13$ & $\mathrm{n}=8$ & $\mathrm{n}=7$ & $\mathrm{n}=2$ \\
\hline Amikacin & $33.33 \%(6)$ & $100 \%(13)$ & $25 \%(2)$ & $0 \%(0)$ & $50 \%(1)$ \\
\hline Amoxiclav & $100 \%(18)$ & $100 \%(13)$ & $100 \%(8)$ & NA & $50 \%(1)$ \\
\hline Cefazolin & $100 \%(18)$ & $53.85 \%(7)$ & $50 \%(4)$ & NA & $100 \%(2)$ \\
\hline Cefepime & $16.67 \%(3)$ & $100 \%(13)$ & $100 \%(8)$ & $100 \%(7)$ & $100 \%(2)$ \\
\hline Cefixime & $22.22 \%(4)$ & $53.85 \%(7)$ & $100 \%(8)$ & NA & $100 \%(2)$ \\
\hline Cefoxitin & $50 \%(9)$ & $100 \%(13)$ & $75 \%(6)$ & $57.14 \%(4)$ & $100 \%(2)$ \\
\hline Cefta-Clav & $27.78 \%(5)$ & $53.85 \%(7)$ & $50 \%(4)$ & $71.43 \%(5)$ & $100 \%(2)$ \\
\hline Ceftazidime & $61.11 \%(11)$ & $100 \%(13)$ & $37.50 \%(3)$ & $42.86 \%(3)$ & $100 \%(2)$ \\
\hline Ceftriaxone & $50 \%(9)$ & $69.23 \%(9)$ & $75 \%(6)$ & $42.86 \%(3)$ & $50 \%(1)$ \\
\hline Cefuroxime & $83.33 \%(15)$ & $61.54 \%(8)$ & $37.50 \%(3)$ & NA & $100 \%(2)$ \\
\hline Ciprofloxacin & $38.89 \%(7)$ & $23.08 \%(3)$ & $50 \%(4)$ & $71.43 \%(5)$ & $100 \%(2)$ \\
\hline Imipenem & $22.22 \%(4)$ & $7.69 \%(1)$ & $0 \%(0)$ & $0 \%(0)$ & $50 \%(1)$ \\
\hline Meropenem & $44.44 \%(8)$ & $15.38 \%(2)$ & $25 \%(2)$ & $28.57 \%(2)$ & $0 \%(0)$ \\
\hline Tigecycline & $0 \%(0)$ & $0 \%(0)$ & $0 \%(0)$ & NA & $50 \%(1)$ \\
\hline Colistin & $0 \%(0)$ & $0 \%(0)$ & $0 \%(0)$ & $0 \%(0)$ & $0 \%(0)$ \\
\hline Clotrimazole & $33.33 \%(6)$ & $46.15 \%(6)$ & $87.50 \%(7)$ & NA & $0 \%(0)$ \\
\hline $\begin{array}{l}\text { Piperacillin } \\
\text { Tazobactam }\end{array}$ & $0 \%(0)$ & $0 \%(0)$ & $0 \%(0)$ & $0 \%(0)$ & $0 \%(0)$ \\
\hline Levofloxacin & $27.78 \%(0)$ & $100 \%(13)$ & $37.50 \%(0)$ & $57.14 \%(4)$ & $100 \%(2)$ \\
\hline \multicolumn{6}{|c|}{ Table 2} \\
\hline
\end{tabular}

\begin{tabular}{|cc|}
\hline Antibiotics & Isolate (Staphylococcus Aureus) \\
Amikacin & $\mathrm{S}$ \\
Amoxiclav & $\mathrm{S}$ \\
Erythromycin & $\mathrm{R}$ \\
Cefazolin & $\mathrm{S}$ \\
Cefotaxime & $\mathrm{S}$ \\
Cefoxitin & $\mathrm{S}$ \\
Cefepime & $\mathrm{S}$ \\
Cotrimoxazole & $\mathrm{S}$ \\
Clindamycin & $\mathrm{R}$ \\
Linezolid & $\mathrm{S}$ \\
Vancomycin & $\mathrm{S}$ \\
\hline Table 3. Staphylococcus aureus was Sensitive to All the \\
Antibiotics Except Clindamycin and Erythromycin \\
\hline
\end{tabular}

\section{DISCUSSION}

This study established that VAP is a vital nosocomial infection among patients receiving mechanical ventilation in MICU. VAP remains a major cause of morbidity and mortality in Intensive care units. The incidence of VAP, its etiology and susceptibility patterns may vary from hospital to hospital and also within the same hospital or ICU over time. Changes in pathogen distribution and antimicrobial susceptibility pattern complicate antibiotic treatment and care of the patients.[6]

Out of 85 cases studied, 50 cases of Ventilator associated pneumonia $60 \%$ were male and $40 \%$ were female patients which is similar to the studies conducted by Golia et al, Gupta et al, and N Chidambaram. ${ }^{[10,11,12]}$

The incidence of VAP reported in our study was $58.82 \%$. Similar study was done by Garg N and Mukhopadhyay et al[13,14] who also reported a very high incidence rate of VAP $(77.2 \%)$ and $(81.7 \%)$ whereas study by Dey et al $(45.4 \%)^{[15]}$ and Jamaati et al (48\%).[16] showed lower incidence rate. 
The isolation rate of Gram negative bacilli in our study was $(96 \%)$. The incidence of VAP was more common in the age group of $46-60$ years $42 \%$ followed by $61-85$ years $36 \%, 31-45$ years $14 \%$ and $18-30$ years $8 \%$ were seen. We compared our results with various studies from India and overseas.

Aetiological causes broadly differs according to the patients in the intensive care unit, their duration of stay in the hospital and previous antimicrobial therapy. Goel et al [17] study shows increase incidence of Acinetobacter baumannii (49.09\%) infections is due to its great resistance to environment which permits it to spread, its inadequate virulence and ability to develop resistance to all antimicrobials and spread by aerosols. Our study is comparable with the Goel et al with increased incidence of Acinetobacter baumannii among all organisms identified i.e. $26 \%$ and its increased multidrug resistance property.

Multi drug resistance is a major threat to VAP patients, 4 (31\%) out of 13 isolates of Acinetobacter baumannii are multidrug resistant which is comparable to study by Goel et al in which $24(44.4 \%)$ out of 27 isolates are multidrug resistant. A study by Harsha V Patil et al[18] showed multi drug resistance predominated by Pseudomonas, E. coli, Klebsiella spp. Acinetobacter spp. and Coagulase positive Staphylococcus aureus. Our study shows the multidrug resistance in Acinetobacter spp. and Klebsiella pneumoniae and Citrobacter freundii.

In our study early onset VAP was $46 \%$ while in various studies found to be $40 \%$. This might be due to antibiotic usage prior to ICU admission.According to our study, colistin, amikacin, carbapenems, tigecycline was highly effective against Acinetobacter spp., while piperacillin tazobactam combination had good activity against P. aeruginosa. So, these two drugs showed good in vitro activity against and in MDR non-fermenters, which was also seen in Kalidas Rit et al study.[19]

Antibiotic such as amikacin, cefoperazone, meropenem and piperacillin tazobactam have been found to the good antibiotic options for VAP which is comparable with the study carried out by Harsha v Patil et al, Akingbade OA et al and OLUGBUE $V$ et al.[18,20,21]

\section{CONCLUSIONS}

Healthcare providers should be, alert and capable of identifying patients at higher risk for VAP and help in applying suitable precautionary measures, including proper positioning and patient care and moderating intervention procedures during management. Good compliance with VAP bundle adopted in critical care areas by the health care workers will reduce the incidence of VAP. Initial and precise diagnosis, proper empirical and precise antimicrobial practice may suggestively recover patients' outcome.

\section{Limitations}

This is a solitary centre study which includes patients from medical ICU, and therefore findings and interpretation of results cannot be generalized to other institutes. The results cannot be applied to other institute, as various factors and bacteriological agents causing VAP may vary from institution to institution.

\section{ACKNOWLEDGEMENT}

Dr. Jayanthi V, Principal and Dean, Sapthagiri Institute of Medical Sciences \& Research Center, \#15, Chikkasandra, Hesaraghatta Main Road, Bangalore-560090. principalsimsrc@gmail.com for supporting our research work.

Dr Hemavathi, MD, Professor and Head of the Department, Department of Microbiology, Sapthagiri Institute of Medical Sciences \& Research Center, \# 15, Chikkasandra, Hesaraghatta Main Road, Bangalore-560090. hemasathyanarayana@gmail.com for supporting our research work.

\section{REFERENCES}

[1] Joseph NM, Sistla S, Dutta TK, et al. Ventilator associated pneumonia in a tertiary care hospital in India-role of multidrug resistant pathogen. J Infect Dis Ctries 2010;4(4):218-25.

[2] American Thoracic Society, Infectious Diseases Society of America. Guidelines for the management of adults with hospital acquired, ventilator-associated and healthcare associated Pneumonia. American Journal of Respiratory and Critical Care Medicine 2005;171(4):388-416.

[3] Ewig S, Torres A, El-Ebiary $M$, et al. Bacterial colonization patterns in mechanically ventilated patients with traumatic and medical head injury. Incidence, risk factors and association with ventilator-associated pneumonia. Am J Respir Crit Care Med 1999;159(1):188-98.

[4] Chastre J, Fagon JY. Ventilator associated pneumonia. AM J Resp Crit Care Med 2002;165(7):867-903.

[5] Celis R, Torres A, Gatell JM, et al. Nosocomial pneumonia: a multivariate analysis of risk and prognosis. Chest 1988;93(2):318-24.

[6] Hunter JD. Ventilator-associated pneumonia. Postgrad Med J 2006;82(965):172-8.

[7] Collee JG, Marmion BP, Fraser AG, et al. Mackie and McCartney's Practical medical microbiology. 14th edn. New York: Churchill Livingstone 1996: p. 978.

[8] CLSI - Clinical and Laboratory Standards Institute 2012. Performance standards for antimicrobial susceptibility testing. Twenty-second informational supplement. Wayne, PA, USA: CLSI, 2012:M100-S22.

[9] Fartoukh M, Maitre B, Honore S, et al. Diagnosing pneumonia during mechanical ventilation: the clinical pulmonary infection score revisited. Am J Respir Crit Care Med 2003;168(2):173-9.

[10] Golia S, Sangeetha KT, Vasudha CL. Microbial profile of early and late onset ventilator associated pneumonia in the Intensive care unit of a tertiary care hospital in Bangalore, India. J Clin Diagn Res 2013;7(11):2462-6. 
[11] Gupta A, Agrawal A, Mehrotra S, et al. Incidence, risk stratification, antibiogram of pathogens isolated and clinical outcome of ventilator associated pneumonia. Indian J Crit Care Med 2011;15(2):96-101.

[12] Chidambaram N, Rajan R, Sasikala G, et al. A study on bacterial etiology of ventilator associated pneumonia and its antimicrobial pattern. International Journal of Contemporary Medical Research 2018;5(12):L5-L8.

[13] Garg N. To determine the bacteriological profile and antibiotic sensitivity pattern of the isolates causing ventilator associated pneumonia in ICU Patients. International Archives of Biomedical and Clinical Research 2018;4:68-71.

[14] Mukhopadhyay C, Bhargava A, Ayyagari A. Role of mechanical ventilation and development of multidrug organisms in hospital acquired pneumonia. Indian J Med Res 2003;118:229-35.

[15] Dey A, Bairy I. Incidence of multidrug-resistant organisms causing ventilator-associated pneumonia in a tertiary care hospital: a nine months' prospective study. Ann Thorac Med 2007;2(2):52-7.

[16] Jamaati HR, Malek MM, Hashemian SMR, et al. Ventilator associated pneumonia: evaluation of etiology, microbiology and resistance patterns in a tertiary respiratory centre. Tanaffos 2010;9(1):21-7.
[17] Goel V, Hogade SA, Karadesai SG. Ventilator associated pneumonia in a medical intensive care unit: Microbial aetiology, susceptibility patterns of isolated microorganisms and outcome. Indian $J$ Anaesth 2012;56(6):558-62.

[18] Patil HV, Patil VC. Incidence, bacteriology and clinical outcome of ventilator-associated pneumonia at tertiary care hospital. Journal of Natural Science, Biology and Medicine 2017;8(1):46-55.

[19] Rit K, Chakraborty B, Saha R, et al. Ventilator associated pneumonia in a tertiary care hospital in India: incidence, etiology, risk factors, role of multidrug resistant pathogens. International Journal of Medicine and Public Health 2014;4(1):51-6.

[20] Akingbade OA, Ogiogwa JI, Okerentugba PO, et al. Prevalence and antibiotic susceptibility pattern of bacterial agents involved in lower respiratory tract infections in Abeokuta, Ogun State, Nigeria. Rep \& Opinion 2012;4(5):25-30.

[21] Olugbue V, Onuoha S. Prevalence and antibiotic sensitivity of bacterial agents involved in lower respiratory tract infections. Int J Biol Chem Sci 2011;5(2):774-81. 